\title{
Development of a vaccine for Chlamydia trachomatis: challenges and current progress
}

This article was published in the following Dove Press journal:

Vaccine: Development and Therapy

17 August 2015

Number of times this article has been viewed

\author{
Louise M Hafner' \\ Peter Timms ${ }^{2}$ \\ 'School of Biomedical Sciences, \\ Institute of Health and Biomedical \\ Innovation, Faculty of Health, \\ Queensland University of Technology, \\ Brisbane, ${ }^{2}$ Faculty of Science, Health, \\ Education and Engineering, University \\ of the Sunshine Coast, Maroochydore \\ DC, QLD, Australia
}

Abstract: Chlamydia trachomatis remains an enigmatic bacterial pathogen with no vaccine yet available to treat human ocular and genital tract infections caused by tissue-tropic serovars of the organism. Globally, it is the leading cause of preventable blindness as well as the leading cause of bacterial sexually transmitted infections. The pathogen has a range of virulence factors that enable it to successfully evade both the innate and adaptive immune system of the host. The host immune system, although protective, paradoxically is also associated closely with the pathologies of trachoma and pelvic inflammatory disease - disease sequelae of some chlamydial infections and reinfections in some genetically susceptible hosts. In this review, we focus on what is known currently about the pathogenesis of ocular and genital infections caused by this mucosal pathogen. We also discuss novel insights into the pathogenesis of infections caused by the genital and ocular serovars of $C$. trachomatis, including a discussion of both pathogen and host factors, such as the human microbiota at these mucosal sites as well as the current immunological challenges facing vaccine development. Finally, we discuss the current progress toward development of a vaccine against $C$. trachomatis. A wide range of recombinant protein antigens are being identified and, hence, are available for vaccine trials. A plasmid-free live strain has recently been produced and evaluated in the mouse (Chlamydia muridarum) and monkey (C. trachomatis) models. The data for ocular infections in the monkey model was particularly encouraging, although the path to regulatory approval of a live vaccine is still uncertain. While still a major challenge, vaccines for ocular and genital C. trachomatis infections are looking more promising.

Keywords: C. trachomatis, ocular and genital infections

\section{Chlamydial epidemiology: global burden of disease}

Chlamydia trachomatis is an obligate intracellular bacterial pathogen primarily of human conjunctival and urogenital columnar epithelial cells. ${ }^{1,2}$ Infections of cells at these mucosal surfaces with tissue-tropic oculogenital serovars of $C$. trachomatis can result in trachoma (ocular serovars $\mathrm{A}, \mathrm{B}, \mathrm{Ba}$, and $\mathrm{C}$ ), ${ }^{3}$ the leading cause of infectious blindness, and can also result in the leading cause of bacterial sexually transmitted infection (STI) (genital serovars D-K, Da, Ia, and Ja). ${ }^{4}$ The STIs can lead to tubal infertility in infected, untreated (or treatment failure) women as a result of ascension of the bacteria into the endometrium and fallopian tubes. ${ }^{5}$ The global burden of these infectious diseases remains a significant public health problem as many primary infections remain undiagnosed and untreated due to the largely asymptomatic nature of each disease. It is estimated that $85 \%$ of women with STIs caused by $C$. trachomatis are asymptomatic. ${ }^{6}$ If left untreated, primary chlamydial infections may also persist
Correspondence: Peter Timms University of the Sunshine Coast, Locked Bag 4, Maroochydore DC, QLD, 4558 Australia

Tel +6I $754565576 ;+6 I 43 I 709745$

Fax +61 754302889

Email ptimms@usc.edu.au submit your manuscript | www.dovepress.com

Dovepress

http://dx.doi.org/1 0.2147/VDT.S69487
Vaccine: Development and Therapy 2015:5 45-58 45

(c) (i) (9) 2015 Hafner and Timms. This work is published by Dove Medical Press Limited, and licensed under Creative Commons Attribution - Non Commercial (unported, v3.0) License. The full terms of the License are available at http://creativecommons.org/licenses/by-nc/3.0/. Non-commercial uses of the work are permitted without any further permiss how to request permission may be found at: http://www.dovepress.com/permissions.php 
for years and cause disease sequelae in some infected hosts. Indeed, it is estimated that up to $40 \%$ of women with an untreated chlamydial genital tract infection develop pelvic inflammatory disease (PID) and also that one in four women with PID will develop infertility. ${ }^{7}$ Repeat detection of C. trachomatis commonly occurs in up to $20 \%$ of patients, ${ }^{8}$ and if the same strain is detected by genotyping but not by culture, this may in fact represent a persistent, rather than a recurrent, infection. ${ }^{9}$

Globally, the World Health Organization (WHO) estimates that annually over 105 million adults have newly acquired STIs caused by $C$. trachomatis. ${ }^{10}$ In the USA, between 2007 and 2012, the overall chlamydial prevalence was $1.7 \%$, suggesting that approximately 1.8 million infections were nationally prevalent among sexually active females aged 14-39 years in this developed country. In those sexually active females aged 14-24 years, chlamydial prevalence was reportedly $4.7 \%$ overall, with $13.5 \%$ prevalence among non-Hispanic blacks. ${ }^{11}$ Notably, however, C. trachomatis STIs are much more important in developing countries, with estimates of 8.3 million new cases in the WHO African Region and 7.2 million new cases in the WHO South-East Asia Region. ${ }^{9}$

Trachoma is responsible for the global visual impairment of approximately 2.2 million people, 1.2 million of whom are irreversibly blind from the disease. Current reports are that 51 countries are known or suspected to be endemic for blinding trachoma, with an additional seven previously endemic countries (Gambia, Ghana, Iran, Morocco, Myanmar, Oman, and Vietnam) reporting that they have now achieved the outcome indicator target for "elimination of blinding trachoma as a public health problem". Despite this encouraging outcome, the 2014 estimate for the global population at risk of trachoma is 232 million people. ${ }^{12}$

Chlamydial disease pathogenesis both for ocular and for genital infections is immune-mediated, with bacterial infections producing inflammatory reactions at both mucosal sites. The immune responses to chlamydial infections are partially protective; however, these local inflammatory reactions often result in asymptomatic infections that can covertly spread to cause tissue damage and scarring complications that can lead to blindness and infertility in a subset of those infected.

Public health programs currently are implemented worldwide in attempts to control for both ocular and genital infections caused by C. trachomatis. The SAFE (Surgery, Antibiotic treatment, Facial cleanliness, and Environmental improvements) strategy is recommended by the WHO for trachoma control primarily to interrupt bacterial transmission. ${ }^{12}$ Worldwide, by the end of 2013, 31 countries reported that they were actively implementing the SAFE strategy. ${ }^{13}$ In addition, national screening programs have been used in many countries for over 20 years along with early treatment interventions for controlling C. trachomatis STIs. ${ }^{14}$ However, both of these public health control programs, although effective at reducing active $C$. trachomatis infections and producing declined rates of disease sequelae, are also problematic. For the STI programs, there are two main problems: first, the greatest areas affected worldwide with these infections, ie, developing countries, have virtually no control programs in place; and second, it is hypothesized (the "arrested immunity" hypothesis ${ }^{15}$ ) that early antibiotic treatment interventions may in fact disrupt the acquisition of protective immunity in these populations. Trachoma elimination efforts also confront major obstacles for the successful implementation of the SAFE program due to conflict and insecurity in several areas of the 46 countries comprising the WHO African Region. A further problem is that the SAFE program involves mass antibiotic treatments of populations which in itself could potentially induce antibiotic resistance.

Obviously the current control programs for ocular and genital infections caused by $C$. trachomatis are suboptimal, with rising reinfection rates still occurring despite, or perhaps even attributed to, some aspects of these control efforts. Thus vaccines that are designed to prevent the acquisition and transmission of chlamydial ocular and genital infections, as well as to prevent the development of immunopathologies following these infections, clearly would be advantageous for controlling trachoma and STIs caused by C. trachomatis.

\section{New insights into $C$. trachomatis pathogenesis}

Infections of ocular and genital mucosae with the genetically similar serovars of $C$. trachomatis damage epithelial cells eliciting complex immune events to control disease outcome. However, chronic inflammatory responses involving both innate and adaptive immunity can have pathological consequences for the host with submucosal tissue remodeling and scarring of the conjunctival surface and fallopian tubes causing the symptomatic diseases of trachoma and PID in some patients.

Disease severity following chronic inflammatory responses to persistent or repeated reinfections is associated with pathogen factors including virulence gene variants and the $C$. trachomatis plasmid. ${ }^{16,17}$ Infection susceptibility and disease pathogenesis is also associated with 
a myriad of host factors including genetic polymorphisms and related immune responses. ${ }^{18,19}$ Changes in bacterial community structures and diversities at the ocular and genital mucosal sites are also important host factors that influence chlamydial disease outcomes. For example, it is becoming increasingly apparent that changes in the conjunctival and vaginal microbiomes of the host occur in trachomatous disease and also influence genital tract infections caused by C. trachomatis. ${ }^{20,21}$

\section{Pathogen factors}

Although the ocular and genital strains of $C$. trachomatis are strictly differentiated, with ocular strains lacking tryptophan synthase function, ${ }^{22}$ the genomes of $C$. trachomatis serovars are more than $99 \%$ identical, ${ }^{23,24}$ and the host-pathogen interactions in chlamydial infections are known to be serovarspecific. A recent report from a Dutch STI clinic showed that in comparison with the other urogenital isolates, serovars $\mathrm{D}$ and $\mathrm{E}$, two of the most prevalent urogenital serovars worldwide, ${ }^{25,26}$ induced the highest serological immunoglobulin $\mathrm{G}$ responses in women with urogenital C. trachomatis infections. ${ }^{27}$ In addition, it has also recently been shown that not only is the host-Chlamydia interaction serovar-specific, but that it is also able to induce different levels of immune responses in disparate host cells. When C. trachomatis serovars $\mathrm{Ba}$ and $\mathrm{D}$ infected monocytes and dendritic cells (DCs), lower levels of inflammatory cytokines were produced in the monocytes allowing the serovars to persist while higher cytokine levels were induced in the DCs causing degradation of serovars in these cells. ${ }^{28}$

\section{Chlamydial plasmid}

Important virulence factors of $C$. trachomatis that link to disease severity include the translocated actin-recruiting phosphoprotein (Tarp) ${ }^{29}$ and the Inc. proteins found on the surface of the parasitophorous compartments (inclusions) inside infected host cells. ${ }^{30}$ Another key C. trachomatis virulence factor is the highly conserved $7.5 \mathrm{kB}$ cryptic plasmid that regulates the transcription of chlamydial plasmidresponsive chromosomal loci ${ }^{31}$ and expression of $p g p 3,{ }^{32}$ the plasmid gene encoding the virulence factor Pgp $3 .{ }^{33}$

Studies using live attenuated chlamydial strains cured of the plasmid reveal that the plasmid contributes both to STI and to blinding trachoma pathogenesis. Genital tract infection of mice with the inflammation-inducing, plasmid-containing wild-type C. trachomatis Lymphogranuloma venereum (LGV) serovar L2 caused infertility in these animals, but infection with the non-inflammation-inducing, plasmid-free strain did not. ${ }^{34}$ The plasmid is also a crucial virulence factor in the nonhuman primate infection model of trachoma, where it has been shown that infections of macaque eyes with $C$. trachomatis organisms lacking the cryptic plasmid are highly attenuated and did not produce measurable ocular clinical pathology in these nonhuman primates,${ }^{17}$ with recent confirmation that loss of pgp3 alone is enough to attenuate the pathogenesis of acute chlamydial conjunctivitis in macaques..$^{35}$ It is also known that the plasmid is not naturally transferred readily between clinical isolates supporting a host-plasmid tropism relationship. ${ }^{36}$ This has been confirmed by recent experiments aimed at developing a transformation system for non-LGV isolates of the ocular tropic $C$. trachomatis serovar A where it was observed that stable plasmid transformants were only obtained when the transforming plasmid shuttle vector was matched with the parental strain. ${ }^{37}$ More recently, transcriptional profiling of cultured human epithelial cells infected with plasmid-deficient and -proficient C. trachomatis organisms has revealed statistically significant increases in the levels of expression of host genes coding for proinflammatory, immune suppression, and cell growth and fibrosis proteins in plasmid-bearing strains ${ }^{38}$ This latter observation further supports the vital role that the chlamydial plasmid plays in immune avoidance and host cell inflammatory responses to C. trachomatis infections. Overall, it is interesting to note that the vast majority of $C$. trachomatis isolates have the plasmid. Naturally occurring plasmid-free strains are very rare. This confirms the central role that the plasmid has for chlamydial virulence and survival. While not proven, the plasmid products may also enhance transmissibility between hosts in some way.

\section{Host factors}

Host factors contributing to $C$. trachomatis disease severity include genetic variation in epithelial cells (eg, interferon [IFN] gamma receptors) and immune cells (eg, human leukocyte antigen [HLA] alleles on monocytes and interleukin [IL]-10 promoter polymorphisms). Indeed, host polymorphisms in immune response genes - immunogenetic risk factors - are known to be significantly associated with susceptibility to, and severity of, $C$. trachomatis-induced inflammatory fibrotic diseases of trachoma and tubal factor infertility (TFI). ${ }^{16}$

In trachoma, several host inflammatory response genes have been identified as contributing to the severity of fibrotic disease leading to conjunctival scarring and trichiasis (turning-in of the eyelashes). ${ }^{39-41}$ For example, part of the host immune system's initial defense against $C$. trachomatis infection is the activation and cytotoxic response of natural 
killer (NK) cells which has been shown to be an important determinant of the severity of active trachoma. ${ }^{42,43}$ Recently, it has been reported that variants of the HLA gene C (HLA-C), in certain combinations with killer-cell immunoglobulinlike receptor (KIR) genes (eg, the $H L A-C 2$ homozygous $K I R 2 D L 2^{+}, K I R 2 D L 3^{+}$genotype), are associated with a sixfold increase in the relative risk of scarring damage in trachoma, and these authors suggest a model of NK-mediated scarring in trachoma in which $H L A-C 2$ genotype favors chronic infection while KIR2DL2/L3 heterozygosity favors chronic inflammation. ${ }^{44}$

Immunogenetic associations are also widely reported in many published studies for $C$. trachomatis-induced genital tract pathology such as TFI. These studies have investigated both immunological regulation of infection focused on genes that code cytokines and HLAs as well as genes related to fibrosis and tissue remodeling such as the matrix metalloproteinases (MMPs). The IL-12-related single nucleotide polymorphism IL12B $1188 \mathrm{~A} / \mathrm{C}$ was reportedly associated with TFI and the severity of tubal damage in a study of 164 TFI women with various degrees of tubal damage, 137 of whom had evidence of a past $C$. trachomatis infection. ${ }^{45}$ The chemokine CXCL13 (the ligand for CXCR5) was induced in fallopian tube tissue following $C$. trachomatis infection of the genital tract ${ }^{46}$ and the frequency of CXCR5 single nucleotide polymorphism $+10950 \mathrm{~T}>\mathrm{C}$ ( $\mathrm{rs}$ 3922) was found to decrease in women who developed tubal pathology after a C. trachomatis infection. ${ }^{47}$

In both ocular and sexually transmitted $C$. trachomatis infections, a specific genotype of the IL-10-coding IL10 gene has been associated with disease. In scarring trachoma, the $I L 10-1082$ GG genotype is associated with an increased risk of trachoma ${ }^{48}$ while the $I L 10-1082 /-819 /-592$ GCC haplotype has been associated with a lower risk of recurrent infection in STIs. ${ }^{49}$ The tumor necrosis factor TNF-308A allele has also been associated with both ocular and genital C. trachomatis disease severity. This allele has been correlated with increased TNF production and increased risk of pathological sequelae in trachoma ${ }^{40}$ and moderate-to-severe adhesions in TFI. ${ }^{44}$

\section{Conjunctival and vaginal microbiomes}

The human microbiome and particularly the diversity of commensal bacteria at healthy conjunctiva ${ }^{50}$ and vagina ${ }^{51}$ is increasingly being investigated for its impact on ocular and reproductive health in humans following infections with the tryptophan auxotroph C. trachomatis.
Of relevance to note here is that: 1) chlamydial growth and development in epithelial cells is inhibited by the cytokine IFN- $\gamma$ that induces indoleamine-2,3-dioxygenase that can catabolize tryptophan ${ }^{52-55}$ and 2) genital (D-K), but not ocular $(\mathrm{A}-\mathrm{C})$, serovars have retained a functional tryptophan synthase that enables them to salvage any indole from their environment and synthesize tryptophan for growth. ${ }^{22}$ Also of note is that tryptophan deficit causes Chlamydia to enter the persistent (viable but non-cultivable ${ }^{56}$ ) growth form (reviewed in ${ }^{57}$ ). The ability of $C$. trachomatis to develop into a persistent form has been suggested as key pathogenetic mechanism underlying ocular and genital infections and the subsequent chronic disease sequelae of blinding trachoma, PID, ectopic pregnancy, and infertility. This is likely in part due to that fact that the persistent form of the organism can evade the host immune response and is more difficult to eliminate with antibiotics. ${ }^{58}$ Subfertile women with tubal pathology also have serological markers of persistent $C$. trachomatis infections and these markers are significantly more common when compared to women without tubal pathology. ${ }^{59}$

The abundance and composition of bacterial communities at the conjunctival site in healthy (or asymptomatic) humans have been characterized using $16 \mathrm{~S}$ deep sequencing of the bacterial ribosomal gene in two studies. The first study was from four healthy American subjects and revealed two prominent non-indole-producing genera, Pseudomonas and Bradyrhizobium, in the ocular microbiomes of the $69.3 \%$ of sequence reads categorized to genus level, in addition to Propionibacterium and Corynebacterium. ${ }^{50}$ However, in contrast to these findings, a more recent study of 105 Gambian participants with normal healthy conjunctivae has reported six genera found in at least $80 \%$ of participants, and these included Corynebacterium, Streptococcus, Propionibacterium, Staphylococcus, Bacillus, and Ralstonia, with Corynebacterium and Streptococcus higher in 115 participants with conjunctival scarring, and with Corynebacterium in even higher abundance in adults with clinical signs of scarring and trichiasis. ${ }^{20}$ Despite the fact that indole-producing Corynebacterium is a predominant component of healthy eyes, this genus has also been reported in trachomatous eyes, ${ }^{60}$ suggesting that changes in the normal conjunctival microbiome occur during trachomatous disease and also suggesting that non-chlamydial bacteria are associated with clinical signs of trachoma. ${ }^{20}$ Interestingly, genital tract serovars of $C$. trachomatis can also cause inclusion conjunctivitis, a sexually transmitted disease that generally follows autoinoculation from contaminated 
genital secretions. ${ }^{61}$ Classically, chlamydial conjunctivitis initially affects one eye and this was reported in a recent case study ${ }^{62}$ It is therefore tempting to speculate that perhaps the indole produced by Corynebacterium is scavenged by the genital strains of $C$. trachomatis that are able to use indole for growth using the functional tryptophan synthase produced by these genital serovars.

In the vaginal microbiome of apparently healthy reproductive-age women, sequencing of ribosomal RNA genes revealed that non-indole-producing Lactobacillus species such as L. iners, L. crispatus, L. gasseri, and L. jensenii comprise $73 \%$ of the bacterial community while the remaining consisted of a large heterogeneous group of strictly anaerobic microorganisms including Prevotella sp. that may express tryptophanase to produce indole. ${ }^{63}$ This latter bacterial community is the common and apparently normal vaginal community found in black and Hispanic women. ${ }^{51}$

Increased risks of acquiring and transmitting STIs such as HIV have been shown to be associated with decreased Lactobacillus species in the vaginal microbiota. ${ }^{64-66}$ The interactions of vaginal microbiota and $C$. trachomatis were recently studied by analyzing the effects of Lactobacillus strains (L. brevis and L. salivarius) on the different phases of C. trachomatis developmental cycle. Lactobacilli had an adverse effect on chlamydial elementary bodies, on chlamydial adsorption to epithelial cells, and on intracellular phases of chlamydial replication. However, lactobacilli had protective effects toward persistent forms of C. trachomatis that were induced by HSV-2 coinfection. ${ }^{67}$ The role of vaginal coinfections on human $C$. trachomatis genital tract infections has recently been reviewed with particularly focus on the suggestion that an altered vaginal microbiome (as occurs in bacterial vaginosis) may provide a source of indole in vivo and that genital chlamydial strains can use indole to grow in this environment. ${ }^{21}$ Lactobacillus strains have also recently been reported to inactivate $C$. trachomatis serovar L2 (the LGV pathogen) primarily through maintaining acidity by producing lactic acid and not through the production of hydrogen peroxide.$^{68}$ Finally, it is also known that the vaginal microbiota is also impacted by sex hormones although the precise mechanisms of the estrogen/Lactobacillus association are yet to be determined. ${ }^{69}$

These novel insights into the interactions of chlamydiae with their ocular and genital host cells, including host genetic polymorphisms and microbiota, need to figure prominently in the deliberations for designing vaccines to treat $C$. trachomatis infections (Figure 1) and are opined in the current literature. ${ }^{69,70}$

\section{The need for chlamydial vaccines}

Given the significant impact of $C$. trachomatis STI and disease worldwide, there continues to be major efforts to control

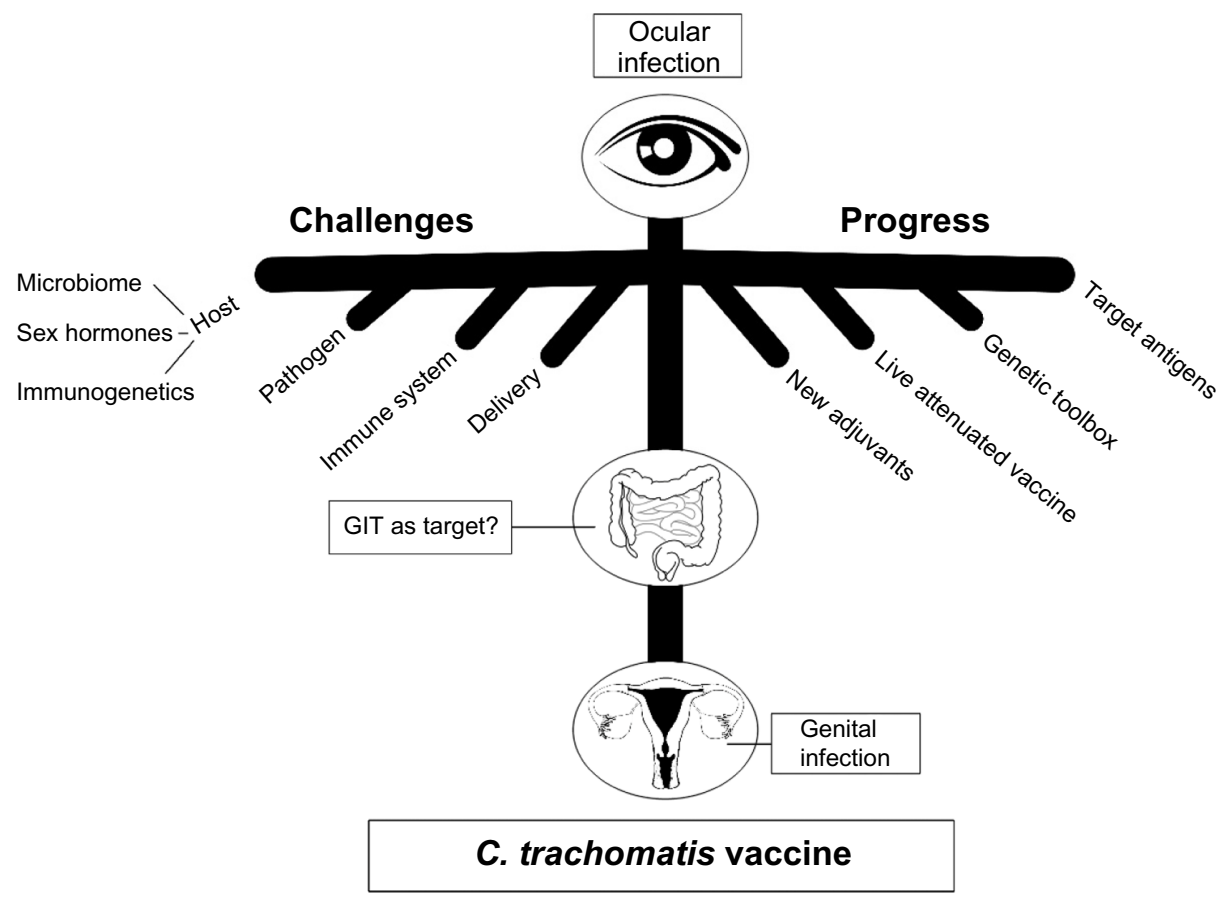

Figure I Summary of current challenges and progress in the development of a vaccine against $C$. trachomatis ocular and genital infections. Abbreviations: C. trachomatis, Chlamydia trachomatis; GIT, gastrointestinal tract. 
it. ${ }^{71}$ These efforts can be divided into primary, secondary, and tertiary strategies. Primary prevention strategies traditionally have focused on education and changing people's behavior and attitudes, and they have been successful in increasing condom use; however, they have had negligible impact on other sexual risk practices. Despite widespread knowledge to the contrary, recent data suggests an increase in the risk factors strongly associated with Chlamydia, such as having multiple sexual partners and overlapping partnerships. ${ }^{72,73}$ While education should continue to be a major control strategy, it is unlikely, on its own, to curb the increasing chlamydial STI rates. Secondary prevention involves screening, or at least testing, and then antibiotic treatment of infected individuals. Prevalence data from the UK and the USA, where over 25\% of young women are screened annually, unfortunately does not show any reduction in prevalence of Chlamydia over time. ${ }^{10,74}$ It is not clear why there is no observed reduction in chlamydial STI rates, when mathematical models suggest that if $20 \%$ of women under 30 years of age are screened each year, the prevalence should be reduced by at least $40 \%{ }^{75}$ One explanation may be the "arrested immunity" hypothesis,$^{15}$ which suggests that early treatment actually prevents the development of any "natural" immunity, making these individuals as equally susceptible as naive individuals to subsequent chlamydial exposure. ${ }^{76}$ The other weakness of secondary prevention is the perceived effectiveness of the most commonly used antibiotic, azithromycin. While azithromycin is very effective in vitro, in practice, there are many more "treatment failures" than originally thought. Treatment failure rates range from $8 \%$ in women ${ }^{77}$ to $20 \%$ in men with "men who have sex with men" infections being particularly challenging. ${ }^{78}$

The reasons for treatment failure are several, including: 1) true antibiotic resistance-unlikely;2) failure of the individual to take the antibiotic - more likely for tetracyclines requiring multiple days of administration, but less likely for singledose azithromycin; 3) different mucosal absorption rates between individuals ${ }^{79}$ and 4) heterotypic resistance in relation to populations of the organism. Tertiary prevention strategies involve targeting the downstream pathology caused by C. trachomatis infections, such as PID, infertility, and ectopic pregnancy. The issues here are that these pathologies are often: 1) asymptomatic, especially for women; 2) poorly diagnosed clinically; and 3) multifactorial. Biomarkers that are predictive of disease are, therefore, urgently needed. For all of these reasons, a vaccine for genital tract infections caused by $C$. trachomatis is considered the only feasible solution.
The greatest demand for control of ocular chlamydial infections leading to trachoma is in the developing world. ${ }^{80}$ While the SAFE strategy does work, the challenge is to deliver it to the poor regions where it is needed. If a vaccine was available for ocular C. trachomatis infections, then this could be utilized in conjunction with the SAFE program and elimination of trachoma may be one step closer.

\section{The immunological challenges Chlamydial immune responses can be partially protective but also can cause pathology}

Protective immune responses to human ocular C. trachomatis infections are not well understood; however, what is known is that protective immunity does develop following natural infections and is associated with reduced incidence and duration of infections. ${ }^{81,82}$ Acquisition of natural immunity is also known to occur following human genital tract $C$. trachomatis infections; however, the time to clear infection can take many months with a long-term follow-up study of the natural course of infection in asymptomatic women reporting that approximately $54 \%$ of the infections were cleared at 1-year follow-up. ${ }^{83,84}$ The risk for PID is also increased following additional exposures to human genital chlamydial infections. ${ }^{85}$ The immune responses to natural human ocular and genital tract infections with $C$. trachomatis thus provide incomplete protection and, in addition, are important in the development of tissue damage and the disease sequelae of blindness and TFI.

The pathogenesis and scarring caused by chlamydial infections has been proposed by Stephens as encompassing two paradigms: the cellular paradigm (epithelial cell layer is sufficient to explain pathology) and the immunological paradigm (in which adaptive immunity explains pathology). ${ }^{86}$

\section{Innate immunity: protection and pathology}

Protection from chlamydial ocular and genital infections involves both innate and adaptive immunity following the initial induction of proinflammatory and chemotactic cytokines such as IL-1 $\alpha$, IL-1 $\beta$, IL-12, and granulocytemacrophage colony-stimulating factor from infected epithelial cells. ${ }^{87-89}$ A subsequent upregulation of these chemokines in Chlamydia-infected epithelial cells recruits innate immune cells to the infection site. For example, recruited to the site of infection following induction of CCL2 and CCL5 are macrophages and DCs; neutrophils 
following chemokine (C-X-C motif) ligand 11 and CXCL8 induction; and also NK cells following CXCL9, CXCL10, and CXCL16 induction. ${ }^{87,90}$ Immune-mediated control of chlamydial growth occurs through the contribution of TNF- $\alpha$ and IFN- $\gamma$ that are released from these immune cells, ${ }^{91}$ noting that IL-12 levels were seen to be increased in the cervical monocytes from women infected with C. trachomatis. ${ }^{92}$ Innate immune pathways are also affected by female sex hormones with the genes for TNF- $\alpha$, IL-17C, and type I and II IFN receptors (among other cytokine genes) upregulated in progesterone-treated endometrial cells that were infected with $C$. trachomatis. ${ }^{93}$ The roles of sex hormones in modulating immune responses in the female genital tract ${ }^{94}$ and particularly in relation to chlamydial infections ${ }^{95}$ have recently been reviewed.

Ocular pathology is related to the collateral tissue damage that occurs following cytokines triggering the initial immune response to chlamydial infections, and these cytokines are prominent both in active and in scarring trachoma. ${ }^{96}$ In children with active trachoma disease, an increase in the neutrophil chemotactic factor CXCL5 has been reported, ${ }^{97,98}$ and increased transcript levels of IL- $1 \beta$ have also been associated with chlamydial infection and active trachoma disease. ${ }^{99,100}$ Conjunctival scarring was also found to be strongly associated with a proinflammatory, innate immune response and with increased expression of (among other factors) IL-1 $\beta$, in a study of 363 trachoma cases. There was also differential expression of MMP-7, -9, -10, and -12 in trachomatis scarring, although the expression of many of these genes was also significantly associated with the presence of non-chlamydial bacterial infection. ${ }^{42}$

An increasing number of studies indicate that innate immune responses to $C$. trachomatis infections arising from the epithelium and innate immune cells, along with changes in MMP activity, are likely to also be important in the development of genital tissue damage and oviduct fibrosis in TFI, with MMP-9 expression enhanced in response to chlamydial infections in vitro in human fallopian tube organ cultures ${ }^{101}$ and from neutrophils in vivo in a murine chlamydial genital tract model. ${ }^{102}$ Fallopian tube scarring associated with $C$. trachomatis genital tract infections may also be the result of increased production of inducible nitric oxide synthase, and mediators such as activins, that are secreted by infected tubal epithelial cells. ${ }^{103}$ Host factors associated with scar formation and other fibrotic conditions were also recently reported as being released from epithelial cell monolayers as soon as 1 hour postinfection with C. trachomatis serovar E, and these findings have formed the basis of a hypothesis involving multiple feedback loops to explain Chlamydia-induced fibrotic scarring of fallopian tubes. ${ }^{104,105}$ These explanations for the pathology induced by chlamydial infections add to previous work showing an involvement of heat shock protein 60 and a proposed model of molecular mimicry which has been discussed extensively by Hafner. ${ }^{105}$

\section{Adaptive immunity: protection and pathology}

Cells of both the humoral (B-cells) and cell-mediated (T-cells) adaptive immune responses are also coordinated with cells of the innate immune response in attempts to protect against chlamydial infections.

Although chlamydiae are intracellular pathogens, and anti-chlamydial antibodies have a major role in protective immunity against chlamydial reinfections, there is increasing evidence that B-cells can protect against infectious agents using antibody-independent mechanisms. ${ }^{106}$

In trachoma, the protective role of antibodies remains to be elucidated, although it is known that the presence or absence of clinical signs of ocular disease is associated with specific antibodies directed against certain chlamydial antigens. $^{107}$

In chlamydial infections of the murine genital tract, it has been reported that a deficiency in B-cells significantly reduced the endogenous Chlamydia-specific CD4+ T-cell responses within the local draining iliac lymph nodes and that infection was disseminated in these mice; thus, one possibility is that B-cells may also act as antigen-presenting cells during primary chlamydial infection and participate with the cell-mediated response in bacterial clearance to prevent chlamydial dissemination. ${ }^{108}$ Alternative possibilities for the potential roles of B-cells in the draining lymph nodes during a primary Chlamydia genital tract infection have also been presented and include an effector function of B-cells to produce cytokines in response to microbial stimulation that may contribute to local defense in the lymph node. ${ }^{109}$ Interestingly, data from studies of autoimmune disease and allergic responses ${ }^{110,111}$ also suggest that B-cells can cause pathology by antibody-independent mechanisms, and since 1) the ascension of chlamydiae from the lower to the upper genital tract and, eventually, infection of oviduct epithelium are prerequisites for the development of long-term sequelae and 2) B-cells are involved in bacterial dissemination and cytokine production, perhaps this is also the case for chlamydial-induced genital tract pathology. 


\section{Acquired immunity and pathology}

Although antibodies are involved in protection against infections caused by C. trachomatis,${ }^{112}$ the most potent host defense mechanism is T-cell immunity, particularly involving the release of IFN- $\gamma$ from host CD4+ and CD8+ T-cells. ${ }^{113-115}$ It also known that IFN- $\gamma$-secreting CD4+T-cells are required to home to the genital mucosa to drive T-cell-mediated protective immunity to chlamydial infections at this site, ${ }^{116}$ and that this is achieved by the adhesion receptor integrin $\alpha 4 \beta 1$ in the murine genital tract. ${ }^{115}$

However, studies in humans have shown that the tissue damage and scarring sequelae of trachoma and TFI are the result of chronic, immunopathogenic responses to the chlamydial organism and are associated with T-helper (Th) cells such as Th1 and Th17.

In active trachoma, the expression of IL-17A, a proinflammatory cytokine (suggesting Th17 cell activity), is significantly increased, ${ }^{97}$ and IL-17A may contribute to fibrosis through epithelial-mesenchymal transition and increased collagen production. ${ }^{117}$ In scarring trachoma, there is also an increased expression of MMP-9 (gelatinase-B), ${ }^{42} \mathrm{a}$ metalloproteinase that is induced not only by NK cells, but also induced and regulated by the Th1 cytokine, IFN- $\gamma ;{ }^{118}$ children with active trachoma also have increased amounts of conjunctival MMP-9. ${ }^{99}$

In the cervical cells collected from Chlamydia-infected women, the levels of IL-17 and IL-22 were significantly higher than the levels of these cytokines observed in noninfected women. ${ }^{119}$ It has also been reported that the levels of IFN- $\gamma$ were significantly higher in the cervical washes of women with recurrent chlamydial infection, as compared to the cytokine levels from women with primary chlamydial genital infections. ${ }^{120}$ In a recent study of 250 women, 59 of whom had TFI, C. trachomatis-infected cells produced significantly higher levels of the IL-12B subunit, p40 than uninfected cells, providing evidence that genetic variation in the IL-12 cytokine family affects $C$. trachomatis-specific immune responses. ${ }^{121}$

Finally, as noted by Mabey et al, "an important difference between ocular and genital infection is that in the eye the damaging sequelae occur at the site of infection, the conjunctival epithelium" while "by contrast in the female genital tract, the major sequelae develop in the fallopian tubes and not at the cervix, which is the site of inoculation" ${ }^{80}$ Nevertheless, the pathology of C. trachomatis infection is similar in the eye and genital tract and involves a complex interaction of innate and adaptive immune responses to the organism that influence both protection and pathology in ocular and sexually transmitted chlamydial infections. Vaccine efforts against this intracellular pathogen will need to ensure that any immune responses generated by the ocular and genital vaccines will include the appropriate populations of innate, $\mathrm{B}$, and T-cells that will engender protection and minimize pathology in the host.

\section{Current progress toward the development of a vaccine Natural infections can induce partial protection, but may also induce immunopathology under some circumstances}

Studies in mice and humans (that have been approved by the relevant animal and human ethics committees) have provided results that support the fact that immunity can develop following natural, live chlamydial infections. In the well-studied Chlamydia muridarum-mouse model, it is well established that following a live intravaginal infection, immunity does develop, with immunized animals very strongly protected against a subsequent live chlamydial challenge dose. ${ }^{122}$ Numerous experiments confirm the fact that major histocompatibility complex (MHC) class II-restricted CD4+ cells and IFN- $\gamma$ are essential for this protection. ${ }^{122,123}$ Antibodies, particularly neutralizing antibodies, are suspected to play some role in the resolution of the primary infection but a much greater role in the resolution of secondary infections. ${ }^{124,125}$ Animals that recover from an initial live chlamydial infection shed virtually no viable organisms upon challenge, a level of protection that, as yet, cannot be replicated using recombinant protein vaccines. However, along with protection against infection in these live infection studies comes severely increased immunopathology. ${ }^{126}$ A similar effect was observed in the early human trachoma vaccine trials in which inactivated whole chlamydial particles did confer some degree of protection, but unfortunately also led to a level of enhanced immunopathology in some vaccinated individuals. ${ }^{86,127}$ There is also good evidence in human genital tract infections that some women at least do develop a level of natural immunity, ${ }^{128}$ with this study showing that $18 \%$ of women attending sexually transmitted disease clinics for C. trachomatis infections naturally resolved their chlamydial infections prior to any antibiotic treatment. In a follow-up study, up to $22 \%$ of women spontaneously resolved their infections, and importantly, these women were significantly less likely to become reinfected, suggesting that their "natural immunity" not only helped them resolve their initial infection, but also protected them from subsequent infections. ${ }^{129}$ 
If we can define the basis of this human protection, while avoiding any adverse immunopathology, then a vaccine against $C$. trachomatis genital tract infections in women should be possible.

\section{The choice of immunogenic target antigens is rapidly expanding}

While early vaccine trials used whole, inactivated chlamydial particles, these will not be acceptable for vaccines as they contain the deleterious antigens that can lead to adverse immunopathology. As a consequence, efforts are now directed primarily toward defined recombinant proteins. While the chlamydial major outer membrane protein (MOMP) dominated early vaccine efforts, the good news is that the era of genome sequencing and reverse genetics has enabled a host of new chlamydial vaccine targets to be investigated. Not surprisingly, surface-exposed membrane proteins such as the MOMP, Omp2, and several Pmps, including PmpD and PmpG, are a major focus. ${ }^{130}$ However, a wide range of intracellular proteins (NrdB, HtrA, GroEL, Nqr3, MAC-perforin, DnaK, IncA) as well as secreted proteins (Tarp, CPAF, CopB) are also showing promise. ${ }^{131-135}$ The strategies for identifying key antigens is also improving. The group of Brunham and colleagues used an immunoproteomic screening approach to identify antigens via their presented T-cell peptides in a $C$. muridarum-infected DC mouse model. ${ }^{136}$ Using this approach, they identified 13 Chlamydia peptides derived from eight novel epitopes presented by MHC class II molecules from bone marrow-derived DCs infected with Chlamydia. While some of the targets overlapped with previously identified targets (PmpG), others were novel (RplF, FabG, AasF, ClpP-1, Gap, PmpE). Other groups have used antigenic profiling of gene expression libraries to identify $C$. trachomatis proteins both with cell-mediated and with humoral immune responses in women with confirmed C. trachomatis genital tract infections, leading to several novel potential vaccine targets. ${ }^{137}$ When they evaluated selected antigens in the urogenital $C$. trachomatis mouse model, perhaps not surprisingly, the balance between cell-mediated and humoral responses differed markedly between the different antigens. ${ }^{138}$

\section{The rapidly expanding chlamydial genetic toolbox should expedite vaccine development}

One aspect that has held the Chlamydia field back is the lack of a genetic transformation system and the ability to test gene mutants. This is one area that is rapidly changing and it should have a significant impact on vaccine development. The chla- mydial genetic transformation conundrum was cracked in 2011 when the group of Clarke et al in Southampton, UK, ${ }^{139}$ showed that it was possible to develop a plasmid vector that contained both the chlamydial endogenous plasmid and an Escherichia coli origin of replication, so that it could shuttle between the two bacterial hosts. By paying careful attention to detail, the genetic transformation of several chlamydial species and strains has now become commonplace. ${ }^{140,141}$ An important addition around the same time was the use of chemical mutagens, such as ethyl methanesulfonate, to generate libraries of chlamydial mutants. ${ }^{142-144}$ Unfortunately, these mutants tend to have multiple mutations, but nevertheless, it is possible to screen such libraries to identify clones with your gene of interest disrupted, and subsequently to evaluate such mutants in vitro. ${ }^{144}$ By complementing the mutated gene with an intact gene on the plasmid shuttle vector, it is now possible to more definitively test the role of key virulence targets. Several of these newly characterized virulence targets are being evaluated as potential vaccine candidates. ${ }^{80}$ While the chlamydial genetic toolbox has expanded significantly over the past few years, it is likely to continue to become easier and easier to manipulate Chlamydia, with both forward and reverse genetics now being possible (eg, targetron approach), and more advanced techniques such as conditional gene silencing and transposon mutagenesis not far off.

\section{Is a live attenuated vaccine the answer?}

For the past 10 years or so, virtually all efforts toward vaccine development have focused on the use of recombinant proteins either singly, or occasionally, as mixtures. Despite all efforts, the levels of "protection" obtained have usually been relatively modest. The general model used to evaluate vaccines has been the C. muridarum-mouse model, although continued excellent work is progressing using the guinea pig model.$^{145-147}$ Protection is usually assessed following live genital tract challenge and is measured by any improvements in infection load (either peak of infection, total infection burden, or days to clearance) or reduction in pathology (physical size of the hydrosalpinx). By all measures, the candidate vaccines have not been able to produce a protective response anywhere near close to elimination of the organism, as can be seen following live infection. The effect on pathology reduction, by comparison, has been more impressive. The other major challenge is how the mouse model data will eventually translate into human studies. Caldwell et a ${ }^{17}$ at the Rocky Mountain Laboratories have attempted to overcome these issues by producing a live, attenuated (plasmid-free) strain of C. trachomatis and have evaluated its effectiveness in the monkey model. Their 
results have been by far the most promising for future vaccine development. Kari et al produced a plasmid-deficient strain of $C$. trachomatis and used it to infect the eyes of cynomolgus macaque monkeys. They showed that, compared to the virulent wild-type strain, the attenuated plasmid-free strain resulted in short-lived infections that resolved spontaneously and, importantly, did not produce ocular pathology. They then challenged the vaccinated monkeys with the virulent wildtype strain. All six unvaccinated animals developed severe pathology and extended infections. By comparison, three of the vaccinated animals were solidly protected, with virtually no infection and no adverse pathology. The other three vaccinated animals showed only partial protection, still having significant infections and pathology; ${ }^{17}$ thus, two major questions remain. First, will a similar protective effect be seen in humans and will it perhaps be HLA-restricted? Second, will it be possible to get approval from the authorities for a live, attenuated chlamydial vaccine?

\section{Should we target gastrointestinal infections in addition to genital tract and ocular infections?}

The final question relates to the site of infection. While there are similarities between ocular and urogenital sites of chlamydial infection, the strains of $C$. trachomatis that infect the sites are different (although there are only very minor genomic differences) and hence it is assumed that there will be two separate vaccines produced. One of the reasons is that the vaccines will most likely be used in very different settings, with the ocular trachoma vaccine being used in lessdeveloped countries where cost and distribution will be major issues, whereas the genital STI vaccine will be used in more affluent regions. In 2013 though, Yeruva et al reported that animals, and presumably humans, are commonly infected in the gastrointestinal tract with Chlamydia. ${ }^{148}$ These infections are generally chronic and exist for long periods of time without evidence of clinical disease. They also proposed that females, in particular, may be at risk of autoinoculation. ${ }^{149}$ These findings suggest that for any chlamydial vaccine to be fully effective, it may make sense to target the chlamydial organisms present at all tissue sites, further challenging the type of immune response that is required.

\section{Future directions}

The pipeline for a protective and yet non-immunopathogenic vaccine against $C$. trachomatis ocular and genital tract infections is looking very promising. We now have a genetic toolbox to manipulate the obligate intracellular pathogen, and this augurs well for exciting rapid developments for a C. trachomatis vaccine. We continue to have an increased understanding of the potential vaccine targets that will best stimulate protective immunity against the pathogen while avoiding the deleterious adverse immunopathological reactions in the host. Microbiomes of the conjunctival and reproductive tracts are becoming increasingly well studied as are the effects of sex hormones estradiol and progesterone on genital and ocular microbiomes, chlamydial infections, and immune responses. The challenges that the organism presents to the host are becoming known, the host responses are being understood, and the progress toward a protective vaccine for $C$. trachomatis infections is occurring at an exponential rate.

Where to from here? The rapidly expanding genetic toolbox means that we should be able to understand and characterize more key chlamydial virulence factors. We should then be able to identify potential new vaccine targets that might enable improved levels of protection above those levels observed with the current vaccine targets. Live attenuated vaccines are certainly one promising direction. Whether it is the plasmid-free strains or specific gene knockouts (not yet possible but perhaps not far off), the level of protection should be significantly better than what can be achieved using recombinant proteins. However, the key question is, will authorities ever approve a live, attenuated chlamydial vaccine? Will partial protection from a vaccine be sufficient to prevent disease sequelae? In fact, should at least some vaccine efforts be directed at vaccines that only target disease, rather than infection? Will the vaccine be able to be delivered to the disease endemic areas of the world? Yes, there are many questions, but with the rapid developments in our knowledge and technological expertise, we are well on the way to deliver protection without the paradoxical pathology of infections caused by the "cloaked" pathogen, ie, C. trachomatis.

\section{Acknowledgment}

The research work of LMH and PT is supported by the Australian NHMRC Grants Scheme.

\section{Disclosure}

The authors report no conflicts of interest in this work.

\section{References}

1. Resnikoff S, Pascolini D, Etya'ale D, et al. Global data on visual impairment in the year 2002. Bull World Health Organ. 2004;82(11): 844-851.

2. Morré SA, Ossewaarde JM, Lan J, et al. Serotyping and genotyping of genital Chlamydia trachomatis isolates reveal variants of serovars Ba, $\mathrm{G}$, and $\mathrm{J}$ as confirmed by omp1 nucleotide sequence analysis. $J$ Clin Microbiol. 1998;36:345-351. 
3. Haggerty CL, Gottlieb SL, Taylor BD, Low N, Xu F, Ness RB. Risk of sequelae after Chlamydia trachomatis genital infection in women. J Infect Dis. 2010;201 Suppl 2:S134-S155

4. Geisler WM, Suchland RJ, Whittington WL, Stamm WE. The relationship of serovar to clinical manifestations of urogenital Chlamydia trachomatis infection. Sex Transm Dis. 2003;30(2):160-165.

5. Peipert JF. Clinical practice. Genital chlamydial infections. $N$ Engl $J$ Med. 2003;349(25):2424-2430.

6. World Health Organisation. Global strategy for the prevention and control of sexually transmitted infections: 2006-2015: Breaking the chain of transmission. Geneva: World Health Organization; 2007.

7. Hosenfeld CB, Workowski KA, Berman S, et al. Repeat infection with chlamydia and gonorrhoea among females: a systematic review of the literature. Sex Trans Dis. 2009;36:478-489.

8. Dean D, Suchland RJ, Stamm WE. Evidence for long-term cervical persistence of Chlamydia trachomatis by omp1 genotyping. $J$ Infect Dis. 2000;182:909-916.

9. World Health Organisation. Global incidence and prevalence of selected curable sexually-transmitted infections -2008 . Geneva: World Health Organization; 2012.

10. Torrone E, Papp J, Weinstock H; Centers for Disease Control and Prevention (CDC). Prevalence of Chlamydia trachomatis genital infection among persons aged 14-39 years - United States, 2007-2012. MMWR Morb Mortal Wkly Rep. 2014;63(38):834-838.

11. Pascolini D, Mariotti SP. Global estimates of visual impairment: 2010. Br J Ophthalmol. 2012;96(5):614-618.

12. World Health Organization. Global elimination of blinding trachoma. Geneva: World Health Organization; 1998. Available from: http:// www.who.int/neglected_diseases/mediacentre/WHA_51.11_Eng.pdf. Accessed April 14, 2015.

13. No authors listed. Alliance for the Global Elimination of Blinding Trachoma by the year 2020. Progress report on elimination of trachoma, 2013. Wkly Epidemiol Rec. 2014;89:421-428. English, French.

14. Johnson RE, Newell WJ, Papp JR, et al. Screening tests to detect Chlamydia trachomatis and Neisseria gonorrhoeae infections - 2002 MMWR Recomm Rep. 2002;51:1-38; quiz CE1-4.

15. Brunham RC, Reckart ML. The arrested immunity hypothesis and the epidemiology of chalmydia control. Sex Trans Dis. 2008;35(1): 53-54.

16. Abdelsamed H, Peters J, Byrne GI. Genetic variation in Chlamydia trachomatis and their hosts: impact on disease severity and tissue tropism. Future Microbiol. 2013;8(9):1129-1146.

17. Kari L, Whitmire WM, Olivares-Zavaleta N, et al. A live-attenuated chlamydial vaccine protects against trachoma in nonhuman primates. J Exp Med. 2011;208(11):2217-2213.

18. Kinnunen AH, Surcel HM, Lehtinen M, et al. HLA DQ alleles and interleukin-10 polymorphism associated with Chlamydia trachomatisrelated tubal factor infertility: a case-control study. Hum Reprod. 2002;17:2071-2078

19. Mei B, Luo Q, Du K, Huo Z, Wang F, Yu P. Association of MICA gene polymorphisms with Chalmydia trachomatis infection and related tubal pathology in infertile women. Hum Reprod. 2009;24:3090-3095.

20. Zhou Y, Holland MJ, Makalo P, et al. The conjunctival microbiome in health and trachomatous disease: a case control study. Genome Med 2014;6:99.

21. Aiyar A, Quayle AJ, Buckner LR, et al. Influence of the tryptophanindole-IFN $\gamma$ axis on human genital Chlamydia trachomatis infection: role of vaginal co-infections. Front Cell Infect Microbiol. 2014;4;72

22. Caldwell HD, Wood H, Crane D, et al. Polymorphisms in Chlamydia trachomatis tryptophan synthase genes differentiate between genital and ocular isolates. J Clin Invest. 2003;111:1757-1769.

23. Brunelle BW, Nicholson TL, Stephens RS. Microarray-base genomic surveying of gene polymorphisms in Chlamydia trachomatis. Genome Biol. 2004;5:R42.

24. Carlson JH, Hughes S, Hogan D, et al. Polymorphisms in the Chlamydia trachomatis cytotoxin locus associated with ocular and genital isolates. Infect Immun. 2004;72:7063-7072.
25. Byrne GI. Chlamydia trachomatis strains and virulence: rethinking links to infection prevalence and disease severity. J Infect Dis. 2010;201 Suppl 2:S126-S133.

26. van Duynhoven YT, Osserwaade JM, Derksen-Nawrocki RP, van der Meijden WI, van der Laar MJ. Chlamydia trachomatis genotypes: correlation with clinical manifestations of infection and patients' characteristics. Clin Infect Dis. 1998,26:314-322.

27. Verweij SP, Lanjouw E, Bax CJ, et al. Serovar D and E of serogroup B induce highest serological responses in urogenital Chlamydia trachomatis infections. BMC Infect Dis. 2014;14:3.

28. Datta B, Njau F, Thalmann J, Haller H, Wagner AD. Differential infection outcome of Chlamydia trachomatis in human blood monocytes and monocyte-derived dendritic cells. BMC Microbiol. 2014;14:209.

29. Zhu S, Feng Y, Chen J, et al. Identification of linear B-cell epitopes within Tarp of Chlamydia trachomatis. J Pept Sci. 2014;20(12):916-922.

30. Gauliard E, Ouellette SP, Rueden KJ, Ladant D. Characterization of interactions between inclusion membrane proteins from Chlamydia trachomatis. Front Cell Infect Microbiol. 2015;5:13.

31. Carlson JH, Whitmire WM, Crane DD, et al. The Chlamydia trachomatis plasmid is a transcriptional regulator of chromosomal genes and a virulence factor. Infect Immun. 2008;76(6):2273-2283.

32. Song L, Carlson JH, Whitmire WM, et al. Chlamydia trachomatis plasmid-encoded Pgp4 is a transcriptional regulator of virulenceassociated genes. Infect Immun. 2013;81:636-644.

33. Li Z, Chen D, Zhong Y, Wang S, Zhong G. The chlamydial plasmidencoded protein pgp3 is secreted into the cytosol of Chlamydia-infected cells. Infect Immun. 2008;76(8):3415-3428.

34. Igietseme JU, Omosun Y, Partin J, et al. Prevention of Chlamydiainduced infertility by inhibition of local caspase activity. J Infect Dis. 2013;207(7):1095-1104.

35. Kari L, Watkins HS, Randall LB, et al. Inactivating pgp3 is sufficient to reproduce the attenuation associated with the loss of the complete Chlamydia trachomatis plasmid in macaques. Thirteenth International Symposium on Human Chlamydial Infections (ISHCI), 2014 ASIOLMAR Conference Grounds in Pacific Grove California; June 22-27, 2014.

36. Seth-Smith HM, Harris SR, Persson K, et al. Co-evolution of genomes and plasmids within Chlamydia trachomatis and the emergence in Sweden of a new variant strain. BMC Genomics. 2009;10:239.

37. Song L, Carlson JH, Zhou B, et al. Plasmid-mediated transformation tropism of chlamydial biovars. Pathog Dis. 2014;70:189-193.

38. Porcella SF, Carlson JH, Sturdevant DE, et al. Transcriptional profiling of human epithelial cells infected with plasmid-bearing and plasmiddeficient Chlamydia trachomatis. Infect Immun. 2015;83(2):534-543.

39. Natividad A, Wilson J, Koch O, et al. Risk of trachomatous scarring and trichiasis in Gambians varies with SNP haplotypes at the interferongamma and interleukin-10 loci. Genes Immun. 2005;6: 332-340.

40. Natividad A, Holland MJ, Rockett KA, et al. Susceptibility to sequelae of human ocular chlamydial infection associated with allelic variation in IL10 cis-regulation. Hum Mol Genet. 2008;17(2):323-329.

41. Natividad A, Hanchard N, Holland MJ, et al. Genetic variation at the TNF locus and the risk of severe sequelae of ocular Chlamydia trachomatis infection Gambians. Genes Immun. 2007;8:288-295.

42. $\mathrm{Hu} \mathrm{VH}$, Weiss HA, Ramadhani AM, et al. Innate immune responses and modified extracellular matrix regulation characterize bacterial infection and cellular/ connective tissue changes in scarring trachoma. Infect Immun. 2012;80:121-130.

43. Natividad A, Freeman TC, Jeffries D, et al. Human conjunctival transcriptome analysis reveals the prominence of innate defense in Chlamydia trachomatis infection. Infect Immun. 2010;78:4895-4911.

44. Roberts $\mathrm{CH}$, Molina S, Makalo P, et al. Conjunctival scarring in trachoma is associated with the HLA-C ligand of KIR and is exacerbated by heterozygosity at KIR2DL2/KIR2DL3. PLoS Negl Trop Dis. 2014; $8(3): \mathrm{e} 2744$.

45. Ohman H. Immunogenetic Risk Factors of Chlamydia-Induced Tubal Factor Infertility [PhD thesis]. Oulu, Helsinki: University of Oulu, University of Helsinki; 2012. 
46. King M, Poya $\mathrm{H}$, Rao J, et al. CXCL13 expression in Chlamydia trachomatis infection of the female reproductive tract. Drugs Today (Barc). 2009;45 Suppl B:125-134.

47. Jiang J, Karimi O, Ouburg S, et al. Interruption of the CXCL13-CXCR5 axis increases upper genital tract pathology and activation of NKT cells following chlamydial genital infection. PLoS One. 2012;7(11):e47487.

48. Mozzato-Chamay N, Mahdi OS, Jallow O, Mabey DC, Bailey RL, Conway DJ. Polymorphisms in candidate genes and risk of scarring trachoma in a Chlamydia trachomatis - endemic population. J Infect Dis. 2000;182(5):1545-1548.

49. Wang C, Tang J, Geisler WM, Crowley-Nowick PA, Wilson CM, Kaslow RA. Human leukocyte antigen and cytokine gene variants as predictors of recurrent Chlamydia trachomatis infection in high-risk adolescents. J Infect Dis. 2005;191(7):1084-1092.

50. Dong Q, Brulc JM, Iovieno A, et al. Diversity of bacteria at healthy human conjunctiva. Invest Ophthalmol Vis Sci. 2011;52(8):5408-5413.

51. Ravel J, Gajer P, Abdo Z, et al. Vaginal microbiome of reproductive-age women. Proc Natl Acad Sci U S A. 2011;108 Suppl 1:4680-4687.

52. Byrne GI, Carlin JM, Merkert TP, Arter DL. Long term effects of gamma interferon on chlamydia-infected host cells: microbiocidal activity follows microbistasis. Infect Immun. 1989;57:1318-1320.

53. Byrne GI, Lehmann LK, Landry GJ. Induction of tryptophan catabolism is the mechanism for gamma-interferon mediated inhibition of intracellular Chlamydia psittaci replication in T24 cells. Infect Immun. 1986;53:347-351.

54. Beatty WL, Belanger TA, Desai AA, Morrison RP, Byrne GI. Tryptophan depletion as a mechanism of gamma interferon-mediated chlamydial persistence. Infect Immun. 1994;62:3705-3711.

55. Brunham RC, Rey-Ladino J. Immunology of Chlamydia infection: implications for a Chlamydia trachomatis vaccine. Nat Rev Immunol. 2005;5:149-161.

56. Hogan RJ, Mathews SA, Mukhopadhyay S, Summersgill JT, Timms P. Chlamydial persistence: beyond the biphasic paradigm. Infect Immun. 2004;72:1843-1855.

57. Wyrick PB. Chlamydia trachomatis persistence in vitro: an overview. J Infect Dis. 2010;201 Suppl 2:S88-S95.

58. Mpiga P, Ravaoarinoro M. Chlamydia trachomatis persistence: an update. Microbiol Res. 2006;161(1):9-19.

59. den Hartog JE, Land JA, Stassen FR, Kessels AG, Bruggeman CA. Serological markers of persistent C. trachomatis infections in women with tubal factor subfertility. Hum Reprod. 2005;20:986-990.

60. Cevallos V, Witcher JP, Melese M, et al. Association of conjunctival bacterial infection and female sex in cicatricial trachoma. Invest Opthamol Vis Sci. 2012;53:5208-5212.

61. Garland SM, Malatt A, Tabrizi S, et al. Chlamydia trachomatis conjunctivitis. Prevalence and association with genital tract infection. Med J Aust. 1995;162:363-366.

62. Sulis G, Urbinati L, Franzoni A, Gargiulo F, Carvalho AC, Matteelli A. Chlamydia trachomatis conjunctivitis in a male teenager: a case report. Infez Med. 2014;22(2):140-143.

63. Sasaki-Imamura T, Yoshida Y, Suwabe K, Yoshimura F, Kato H. Molecular basis of indole production catalysed by tryptiphanase in the genus Prevotella. FEMS Microbiol Lett. 2011;322:51-59.

64. Mirmonsef P, Krass L, Landay A, Spear GT. The role of bacterial vaginosis and trichomonas in HIV transmission across the female genital tract. Curr HIV Res. 2012;10(3):202-210.

65. Mitchell C, Balkus JE, Fredricks D, et al. Interaction between lactobacilli, bacterial vaginosis associated bacteria, and HIV Type 1 RNA and DNA Genital shedding in US and Kenyan women. AIDS Res Hum Retroviruses. 2013;29(1):13-19.

66. Sha BE, Zariffard MR, Wang QJ, et al. Female genital-tract HIV load correlates inversely with Lactobacillus species but positively with bacterial vaginosis and Mycoplasma hominis. J Infect Dis. 2005;191(1):25-32.

67. Mastromarino P, Di Pietro M ,Schiavoni G, Nardis C, Gentile M, Sessa R. Effects of vaginal lactobacilli in Chlamydia trachomatis infection. Int J Med Microbiol. 2014;304(5-6):654-661.
68. Gong Z, Luna Y, Yu P, Fan H. Lactobacilli inactivate Chlamydia trachomatis through lactic acid but not H2O2. PLoS One. 2014;9(9): e107758.

69. Brotman RM, Ravel J, Bavoil PM, Gravitt PE, Ghanem KG. Microbiome, sex hormones, and immune responses in the reproductive tract: challenges for vaccine development against sexually transmitted infections. Vaccine. 2014;32:1543-1552.

70. Ferreira RB, Antunes LC, Finlay BB. Should the human microbiome be considered when developing vaccines? PLoS Pathog. 2010;6:e1001190.

71. Gottlieb SL, Low N, Newman LM, Bolan G, Kamb M, Broutet N. Toward global prevention of sexually transmitted infections (STIs): the need for STI vaccines. Vaccine. 2014;32:1527-1535.

72. de Visser RO, Badcock PB, Rissel C, et al. Safer sex and condom use: findings from the Second Australian Study of Health and Relationships. Sex Health. 2014;11(5):495-504.

73. Sonnenberg P, Clifton S, Beddows S, et al. Prevalence, risk factors, and uptake of interventions for sexually transmitted infections in Britain: findings from the National Surveys of Sexual Attitudes and Lifestyles (Natsal). Lancet. 2013;382(9907):1795-1806.

74. Low N, Bender N, Nartey L, Shang A, Stephenson JM. Effectiveness of chlamydia screening: systematic review. Int J Epidemiol. 2009;38: 435-448.

75. Regan DG, Wilson DP, Hocking JS. Coverage is the key for effective screening of Chlamydia trachomatis in Australia. JID. 2008;198(3): 349-358.

76. Brunham RC, Rappuoli R. Chlamydia trachomatis control requires a vaccine. Vaccine. 2013;31(15):1892-1897.

77. Walker J, Tabrizi SN, Fairley CK, et al. Chlamydia trachomatis incidence and re-infection among young women - behavioural and microbiological characteristics. PloS One. 2012;7(5):e37778.

78. Kong FY, Tabrizi SN, Law M, et al. Azithromycin versus doxycycline for the treatment of genital chlamydia infection: a meta-analysis of randomized controlled trials. Clin Infect Dis. 2014;59(2):193-205.

79. Liu B, Guy R, Donovan B, Kaldor JM. Chlamydia trachonatis reinfections in a population-based cohort of women. Sex Trans Infect. 2013;89(1):45-50.

80. Mabey DC, Hu V, Bailey RL, Burton MJ, Holland MJ. Towards a safe and effective chlamydial vaccine: Lessons from the eye. Vaccine. 2014;32:1572-1578.

81. Bailey R, Duong T, Carpenter R, Whittle H, Mabey D. The duration of human ocular Chlamydia trachomatis infection is age dependent. Epidemiol Infect. 1999;123:479-486.

82. Grassly NC, Ward ME, Ferris S, Mabey DC, Bailey RL. The natural history of trachoma infection and disease in a Gambian cohort with frequent follow-up. PLoS Negl Trop Dis. 2008;2(12):e341.

83. Molano M, Meijer CJ, Weiderpass E, et al. The natural course of Chlamydia trachomatis infection in asymptomatic Colombian women: a 5-year follow-up study. J Infect Dis. 2005;191(6):907-916.

84. Geisler WM. Duration of untreated, uncomplicated Chlamydia trachomatis genital infection and factors associated with chlamydia resolution: a review of human studies. J Infect Dis. 2010;201 Suppl 2:S104-S113.

85. Ness RB, Soper DE, Richter HE, et al. Chlamydia antibodies, Chlamydia heat shock protein, and adverse sequelae after pelvic inflammatory disease: the PID Evaluation and Clinical Health (PEACH) Study. Sex Transm Dis. 2008;35(2):129-135.

86. Stephens RS. The cellular paradigm of chlamydial pathogenesis. Trends Microbiol. 2003;11:44-51.

87. Rasmussen SJ, Eckmann L, Quayle AJ, et al. Secretion of proinflammatory cytokines by epithelial cells in response to Chlamydia infection suggests a central role for epithelial cells in chlamydial pathogenesis. $J$ Clin Invest. 1997;99:77-87.

88. Darville T, Hiltke TJ. Pathogenesis of genital tract disease due to Chalmydia trachomatis. J Infect Dis. 2010;201 Suppl 2:S114-S125.

89. Johnson RM. Murine oviduct epithelial cell cytokine responses to Chlamydia muridarum infection include interleukin-12-p70 secretion. Infect Immun. 2004;72:3951-3960. 
90. Bucholz KR, Stephens RS. Activation of the host cell proinflammatory interleukin- 8 response by Chlamydia trachomatis. Cell Microbiol. 2006;8:1768-1779.

91. Roan NR, Starnbach MN. Immune-mediated control of Chlamydia infection. Cell Microbiol. 2008;10:9-19.

92. Agrawal T, Bhengraj AR, Vats V, Salhan S, Mittal A. Expression of TLR 2, TLR 4 and iNOS in cervical monocytes of Chlamydia trachomatisinfected women and their role in host immune response. Am J Reprod Immunol. 2011;66(6):534-543.

93. Wan C, Latter JL, Amirshahi A, et al. Progesterone activates multiple innate immune pathways in Chlamydia trachomatis-infected endocervical cells. A J Reprod Immunol. 2014;71:165-177.

94. Wira CR, Rodriguez-Garcia M, Patel MV. The role of sex hormones in immune protection of the female reproductive tract. Nat Rev Immunol 2015; 15:217-230.

95. Hafner LM, Cunningham K, Beagley KW. Ovarian steroid hormones: effects on immune responses and Chlamydia trachomatis infections of the female genital tract. Mucosal Immunol. 2013;6:859-875.

96. Burton MJ, Rajak SN, Bauer J, et al. Conjunctival transcriptome in scarring trachoma. Infect Immun. 2011;79:499-511.

97. Burton MJ, Ramadhani A, Weiss HA, et al. Active trachoma is associated with increased conjunctival expression of IL17A and profibrotic cytokines. Infect Immun. 2011;79:4977-4983.

98. Hu VH, Holland MJ, Burton MJ. Trachoma: protective and pathogenic ocular immune responses to Chlamydia trachomatis. PLoS Neglected Trop Dis. 2013;7(2):e2020.

99. Burton MJ, Bailey RL, Jeffries D, Mabey DC, Holland MJ. Cytokine and fibrogenic gene expression in the conjunctivas of subjects from a Gambian community where trachoma is endemic. Infect Immun 2004;72:7352-7356.

100. Bobo L, Novak N, Mkocha H, Vitale S, West S, Quinn TC. Evidence for a predominant proinflammatory conjunctival cytokine response in individuals with trachoma. Infect Immun. 1996;64:3273-3279.

101. Ault KA, Kelly KA, Ruther PE, et al. Chlamydia trachomatis enhances the expression of matrix metalloproteinases in an in vitro model of the human fallopian tube infection. Am J Obstet Gynecol. 2002;187(5):1377-1383.

102. Ramsey KH, Sigar IM, Schripsema JH, Shaba N, Cohoon KP. Expression of matrix metalloproteinases subsequent to urogenital Chlamydia muridarum infection of mice. Infect Immun. 2005;73(10):6962-6973.

103. Refaat B, Al-Azemi M, Geary I, Eley A, Ledger W. Role of activins and inducible nitric oxide in the pathogenesis of ectopic pregnancy in patients with or without Chlamydia trahomatis infection. Clin Vaccine Immunol. 2009;16(10):1493-1503.

104. Humphrys MS, Creasy T, Sun Y, et al. Simultaneous transcriptional profiling of bacteria and their host cells. PLoS One. 2013;8(12): e80597.

105. Hafner LM. Pathogenesis of fallopian tube damage caused by Chlamydia trachomatis infections. Contraception. Epub 2015 January 13.

106. León B, Ballesteros-Tato A, Misra RS, Wojciechowski W, Lund FE. Unraveling effector functions of B cells during infection: the hidden world beyond antibody production. Infect Disord Drug Targets. 2012;12(3):213-221.

107. Lu C, Holland MJ, Gong S, et al. Genome-wide identification of Chlamydia trachomatis antigens associated with trachomatous trichiasis. Ivest Opthamol Vis Sci. 2012;53:2551-2559.

108. Li LX, McSorley SJ. B cells enhance antigen-specific CD4 T cell priming and prevent bacteria dissemination following Chlamydia muridarum genital tract infection. PLoS Pathog. 2013;9:e1003707.

109. Li LX, McSorley SJ. A re-evaluation of the role of B cells in protective immunity to Chlamydia infection. Immunol Lett. 2015;164:88-93.

110. Drolet JP, Frangie H, Guay J, Hajoui O, Hamid Q, Mazer BD. B lymphocytes in inflammatory airway diseases. Clin Exp Allergy. 2010;40(6):841-849.

111. Townsend MJ, Monroe JG, Chan AC. B-cell targeted therapies in human autoimmune diseases: an updated perspective. Immunol Rev. 2010;237(1):264-283.
112. Su H, Feizler K, Caldwell HD, Morrison RP. Chlamydia trachomatis genital tract infections of antibody-deficient gene knockout mice. Infect Immun. 1997;65:1993-1999.

113. Gondek DC, Roan NR, Starnbach MN. T cell responses in the absence of IFN-gamma exacerbate uterine infection with Chlamydia trachomatis. J Immunol. 2009;183:1313-1319.

114. Johansson M, Schön K, Ward M, Lycke N. Genital tract infection with Chlamydia trachomatis fails to produce protective immunity in gamma-interferon receptor-deficient mice despite a strong local immunoglobulin A response. Infect Immun. 1997;65:1032-1044.

115. Davila SJ, Olive AJ, Starnbach MN. Integrin $\alpha 4 \beta 1$ is necessary for CD4+ T cell-mediated protection against genital Chlamydia trachomatis infection. J Immunol. 2014;192:4284-4293.

116. Johansson M, Lycke N. Immunological memory in B-cell-deficient mice conveys long-lasting protection against genital tract infection with Chlamydia trachomatis by rapid recruitment of T cells. Immunology. 2001;102:199-208

117. Mi S, Li Z, Yang HZ, et al. Blocking IL-17A promotes the resolution of pulmonary inflammation and fibrosis via TGF-beta-1 dependent and -independent mechanisms. J Immunol. 2011;187:3003-3014.

118. Springall R, Amezcua-Guerra LM, Gonzalez-Pacheco H, et al. Interferon-gamma increases the ratio of matrix metalloproteinase-9/tissue inhibitor of metalloproteinase-1 in peripheral monocytes from patients with coronary artery disease. PLoS One. 2013;8(8):e72291.

119. Jha R, Srivastava P, Salhan S, et al. Spontaneous secretion of interleukin-17 and -22 by human cervical cells in Chlamydia trachomatis infection. Microbes Infect. 2011;13(2):167-178.

120. Agrawal T, Vats V, Salhan S, Mital A. Mucosal and peripheral immune responses to chlamydial heat shock protein in women infected with Chlamydia trachomatis. Clin Exp Immunol. 2007;148:461-468.

121. Öhman H, Natividad A, Bailey R, et al. Contribution of IL-12A and IL-12B polymorphisms to Chlamydia trachomatis-specific cellmediated immune responses. Scand J Immunol. 2015;81(3):209-213.

122. O’Meara CP, Armitage CW, Harvie MC, Timms P, Lycke NY, Beagley KW. Immunization with a MOMP-based vaccine protects against a pulmonary Chlamydia challenge and identifies a disconnection between infection and pathology. PLoS One. 2013;8(4):e61962.

123. Hafner LM, Timms P. Chlamydia. In: Stanberry LR, Rosenthal SL, editors. Sexually Transmitted Diseases. 2nd Edition. Waltham: Elsevier; 2013:369-410

124. Morrison SG, Morrison RP. A predominant role for antibody in acquired immunity to chlamydial genital tract reinfection. J Immunol. 2005;175(11):7536-7542.

125. Farris CM, Morrison RP. Vaccination against Chlamydia genital infection utilizing the murine C. muridarum model. Infect Immun. 2011;79(3):986-996.

126. Carey AJ, Cunningham KA, Hafner LM, Timms P, Beagley KW. Effects of inoculating dose on the kinetics of Chlamydia muridarum genital infection in female mice. Immunol Cell Biol. 2009;87(4):337-343.

127. Grayston JT, Woolridge RL, Wang SP, et al. Field studies of protection from infection by experimental trachoma virus vaccine in preschoolaged children on Taiwan. Proc Soc Exp Biol Med. 1963;112: 589-595.

128. Geisler WM, Wang C, Morrison SG, Black CM, Bandea CI, Hook EW 3rd. The natural history of untreated Chlamydia trachomatis infection in the interval between screening and returning for treatment. Sex Trans Dis. 2008;35(2):119-123.

129. Geisler WM, Lensing SY, Press CG, Hook EW 3rd. Spontaneous resolution of genital Chlamydia trachomatis infection in women and protection from reinfection. J Infect Dis. 2013;207(12):1850-1856.

130. Hafner LM, Wilson DP, Timms P. Development status and future prospects for a vaccine against Chlamydia trachomatis infection. Vaccine. 2014;32(14):1563-1571

131. Barker CJ, Beagley KW, Hafner LM, Timms P. In silico identification and in vivo analysis of a novel T-cell antigen from Chlamydia, NrdB. Vaccine. 2008;26:1285-1296. 
132. Finco O, Frigimelica E, Buricchi F, et al. Approaches to discover T- and B-cell antigens of the intracellular pathogens applied to the design of Chlamydia trachomatis vaccine. Proc Natl Acad Sci U S A. 2011;108:9969-9974.

133. Coler RN, Bhatia A, Maisonneuve JF, et al. Identification and characterisation of novel recombinant vaccine antifens for immunization against genital Chlamydia trachomatis. FEMS Immunol Med Microbiol. 2009;55:258-270.

134. Wang J, Chen I, Chen F, et al. A chlamydial type III-secreted effector protein (Tarp) is predominantly recognized by antibodies from humans infected with Chlamydia trachomatis and induces protective immunity against upper genital tract pathologies in mice. Vaccine. 2009;27:2967-2980

135. Murthy AK, Cong Y, Murphey C, et al. Chlamydial protease-like activity factor induces protective immunity against genital chlamydial infection in transgenic mice that express the human HLA-DR4 allele. Infect Immun. 2006;74:6722-6729.

136. Yu H, Jiang X, Shen C, et al. Chlamydia muridarum T-cell antigens formulated with the adjuvant DDA/TDB induce immunity against infection that correlates with a high frequency of gamma interferon (IFN-gamma)/tumor necrosis factor alpha and IFN-gamma/ interleukin-17 double-positive CD4+T cells. Infect Immun. 2010;78(5): 2272-2782.

137. Follmann F, Olsen AW, Jensen KT, Hansen PR, Andersen P, Theisen M. Antigenic profiling of a Chlamydia trachomatis gene expression library. J Infect Dis. 2008;197:897-905.

138. Olsen AW, Follmann F, Erneholm K, Rosenkrands I, Andersen P. Protection Against Chlamydia trachomatis Infection and Upper Genital Tract Pathological Changes by Vaccine-Promoted Neutralizing Antibodies Directed to the VD4 of the Major Outer Membrane Protein. J Infect Dis. Epub 2015 March 6.

139. Wang Y, Kahane S, Cutcliffe LT, Skilton RJ, Lambden PR, Clarke IN. Development of a transformation system for Chlamydia trachomatis: restoration of glycogen biosynthesis by acquisition of a plasmid shuttle vector. PLoS Pathog. 2011;7(9):e1002258.
140. Ramsey KH, Schripsema JH, Smith BJ, et al. Plasmid CDS5 influences infectivity and virulence in a mouse model of Chlamydia trachomatis urogenital infection. Infect Immun. 2014;82(8):3341-3349.

141. Nguyen BD, Valdivia RH. Forward genetic approaches in Chlamydia trachomatis. J Vis Exp. 2013;(80):e50636.

142. Kari L, Goheen MM, Randall LB, et al. Generation of targeted Chlamydia trachomatis null mutants. Proc Natl Acad Sci U S A. 2011; 108(17):7189-7193.

143. Snavely EA, Kokes M, Dunn JD, et al. Reassessing the role of the secreted protease CPAF in Chlamydia trachomatis infection through genetic approaches. Pathog Dis. 2014;71(3):336-351.

144. Kari L, Southern TR, Downey CJ, et al. Chlamydia trachomatis polymorphic membrane protein $\mathrm{D}$ is a virulence factor involved in early host-cell interactions. Infect Immun. 2014;82(7):2756-2762.

145. Andrew DW, Hafner LM, Beagley KW, Timms P. Partial protection against chlamydial reproductive tract infection by a recombinant major outer membrane protein/CpG/cholera toxin intranasal vaccine in the guinea pig Chlamydia caviae model. J Reprod Immunol. 2011;91(1-2):9-16.

146. Wali S, Gupta R, Veselenak RL, et al. Use of a Guinea pig-specific transcriptome array for evaluation of protective immunity against genital chlamydial infection following intranasal vaccination in Guinea pigs. PLoS One. 2014;9(12):e114261.

147. Neuendorf E, Gajer P, Bowlin AK, et al. Chlamydia caviae infection alters abundance but not composition of the guinea pig vaginal microbiota. Pathog Dis. 2015;73(4).

148. Yeruva L, Spencer N, Bowlin AK, Wang Y, Rank RG. Chlamydial infection of the gastrointestinal tract: a reservoir for persistent infection. Pathog Dis. 2013;68(3):88-95.

149. Rank RG, Yeruva L. Hidden in plain sight: chlamydial gastrointestinal infection and its relevance to persistence in human genital infection. Infect Immun. 2014;82(4):1362-1371.
Vaccine: Development and Therapy

\section{Publish your work in this journal}

Vaccine: Development and Therapy is an international, peer-reviewed, open access journal that spans the spectrum of vaccine design and development through to clinical applications. The journal is characterized by the rapid reporting of application notes, reviews, original research and clinical studies in all therapeutic areas. Clinical outcomes, patient safety,

\section{Dovepress}

and programs for the development and effective, safe, and sustained use of vaccines will be a feature of the journal. The manuscript management system is completely online and includes a very quick and fair peer-review system. Visit http://www.dovepress.com/testimonials.php to read real quotes from published authors. 